This is an electronic reprint of the original article. This reprint may differ from the original in pagination and typographic detail.

Author(s): Hämäläinen, Raija; Oksanen, Kimmo

Title: $\quad$ Collaborative 3D learning games for future learning: teachers' instructional practices to enhance shared knowledge construction among students

Year: $\quad 2014$

Version:

Please cite the original version:

Hämäläinen, R., \& Oksanen, K. (2014). Collaborative 3D learning games for future learning: teachers' instructional practices to enhance shared knowledge construction among students. Technology, Pedagogy and Education, 23(1), 81-101. https://doi.org/10.1080/1475939X.2013.838451

All material supplied via JYX is protected by copyright and other intellectual property rights, and duplication or sale of all or part of any of the repository collections is not permitted, except that material may be duplicated by you for your research use or educational purposes in electronic or print form. You must obtain permission for any other use. Electronic or print copies may not be offered, whether for sale or otherwise to anyone who is not an authorised user. 


\title{
Collaborative 3D learning games for future learning: Teachers' instructional practices to enhance shared knowledge construction among students
}

\author{
Raija Hämäläinen* \& Kimmo Oksanen
}

Special Issue of Technology, Pedagogy and Education; Schools for the Future: Subtle shift or seismic change?

Finnish Institute for Educational Research, University of Jyväskylä.

Keskussairaalantie 2, P.O. Box 35, FI-40014 University of Jyväskylä, Finland

Tel +358408054250

Fax +35814617418

raija.h.hamalainen@jyu.fi

*Corresponding author

Adjunct professor (PhD) Raija Hämäläinen works at the Finnish Institute for Educational Research, University of Jyväskylä, Finland. Hämäläinen has designed long-term research project (as a joint effort with Jyväskylä College - ongoing since 2004) that focuses on designing and investigating new learning spaces for the future. Her main research interest deal with orchestrating collaborative learning processes and scripted computer-supported collaborative learning in technology-enhanced learning (TEL) environments. Her research has been based on active international collaboration in theoretical and design issues of TEL. The international collaboration includes for example visits to international research groups and joint international high-level publishing. Her recent publications include articles in Computers \& Education, Educational Research Review, Teaching and Teacher Education, Computers in Human Behavior, and Technology, Pedagogy and Education.

LicEd. Kimmo Oksanen is a PhD student at the Finnish Institute for Educational Research, University of Jyväskylä, Finland. Oksanen has participated in the long-term research project which deals with collaborative learning in serious games. His research interests include serious game design, and supporting and evaluating collaborative learning in serious games. 


\section{Collaborative 3D learning games for future learning: Teachers' instructional practices to enhance shared knowledge construction among students}

Collaborative games will enable new kinds of possibilities for learning. In the future, the goal of game-based learning should be to introduce new ideas and deepen in-depth understanding of learners. However, studies have shown that shared high-level knowledge construction is a challenging process. Moreover, thus far, few empirical studies have examined what constitutes the teacher's role in games. The focus of this paper is to investigate teachers' real-time instructional activities in a scripted 3D game setting. Our hypothesis is that groups with real-time teacher instruction will come up with more shared knowledge construction that can be considered productive than groups studying without real-time teacher instruction. Thus, content analysis was conducted to compare collaboration processes between different learning conditions. This study indicates that the teacher has a special role in empowering collaborative knowledge construction in the $3 \mathrm{D}$ game context in vocational education. Our findings show that the teacher's participation in collaborative work helps groups to develop productive ways of providing knowledge and asking contextual questions. In addition, we illustrate the teacher's ability to bring about students in formulating hypotheses, interpreting context, providing explanations, and describing observations.

Keywords: Serious games; collaborative learning; teachers' instructional activity; CSCL

\section{Introduction}

Technological developments permit ever more diverse ways of designing digital learning spaces for the future. These virtual learning environments will enable new kinds of activities to supplement traditional classroom practices. With the help of these new learning spaces and environments, vocational students can practice different worklife situations. For example, there is a long history of using simulations and games in 
support of individual learning in vocational learning (e.g., training pilots). Currently, in addition to individual learning, there is also a growing interest in the study of collaborative learning, and of how social skills can be more effectively rehearsed in game environments.

Virtual games provide fruitful ground for practicing collaboration ${ }^{1}$ in a natural way, since gaming often involves solving different kinds of puzzles collaboratively. In addition, games can offer users very attractive and engaging experiences (Lindley, Nacke, \& Sennersten, 2008). Thus, multiplayer games have become increasingly popular. Along with this development, there is a growing interest in applying games to support collaboration (e.g., Silseth, 2012; Villalta, Gajardo, Nussbaum, Andreu, Echeverría, \& Plass 2011). According to Whitton (2010), perceiving these games as fundamental collaborative learning environments is an important step towards making full use of their potential as learning tools. The main idea behind this understanding is that the educational applications support collaborative learning processes in which students' natural motivations and interests enable problem solving. The goal is to make the game environments inherently attractive so that they will "hook" learners to strive to reach shared goals (Papastergiou, 2009).

Whitton (2010) proposes that the crucial value of games lies in their ability to engage students through challenging and meaningful tasks, as well as through interaction with the game and other players. It has been argued that the advantage of multiplayer games is that players can learn how to (a) interact with each other, (b) engage in social problem solving, and (c) actively seek new information while combining existing knowledge to solve problems or tasks to move forward in the game (Gee, 2007; Prensky, 2007). Games can also bring to the classroom learning material and concepts that are difficult to demonstrate and/or explain through traditional means, 
such as practicing authentic electrical hazard situations (Hämäläinen, 2011). Thus, it is understandable that educators have high expectations in general in terms of learning from games. Indeed, the design of future learning environments is promising. A growing field of research on the educational uses of games indicates that games can be helpful in assessing students' understanding as well as integrating their knowledge and skills (e.g., Bagley \& Shaffer, 2009; Rieber \& Noah, 2008).

Despite the growing interest in games for collaborative learning, few studies to date have focused in on the critical aspects of game-based learning (Vandercruysse, Vandewaetere, \& Clarebout, 2011). According to Connolly and colleagues (2012), so far only a few studies have provided evidence that games are actually useful in promoting higher-order learning and/or social skills. Thus, there exists a notion that, at their worst, games give way to empty banter, ineffective use of time, and little learning. On the other hand, applying blanket optimism to the learning potential of games can lead to meaningless use of time wherein entertainment becomes the main purpose of the activity.

The history of simulation studies offers knowledge that may be helpful in designing learning games (for a history of simulations, see De Jong \& van Joolingen, 1998). For example, one key challenge when using simulations has been how to generate an in-depth understanding of content (De Jong, 2006), as improved visualizations do not necessarily translate into better learning. In addition, it has been claimed that without the proper interaction of teachers, the full potential of simulations (e.g., their suitability for practicing inquiry skills) may remain out of reach (Rutten, van Joolingen \& van der Veen, 2012). In light of these challenges learned from studying the long history of simulation studies, it becomes essential to pay attention to how game 
environments are designed to deepen learners' understanding of the content, and also to critically evaluate what the teacher's role is in game spaces.

Collaboration in game environments takes place in many ways: by distributing participants' own expertise and thoughts; by following others' actions; by listening to and elaborating on the views of others; and by participating in the shared knowledge construction of different ideas, hypotheses, and conclusions (Hämäläinen \& Vähäsantanen, 2011). Recent results on collaborative learning have shown that shared knowledge construction is a challenging and multi-faceted process influenced by several contextual factors - namely, students' own lives and experiences (Arvaja, 2012). In reality, this kind of ideal group activity is very challenging; it has been observed that reaching high levels of learning in collaborative activities is less frequent than is presumed (Baker, 2010).

In response to this shortfall, collaboration scripts have been introduced as a way to whet learners' appetites for group work and to ultimately empower collaborative learning. The aim of the scripts is to bolster collaborative activities by guiding interaction processes towards the shared construction of knowledge (Kobbe et al., 2007). In practice, scripts can be integrated into the game design by writing a game story that leads learners into group situations where assisted roles support collaboration (e.g., solving socio-cognitive conflicts).

Despite the promising results regarding collaboration scripts (e.g., Weinberger, Ertl, Fischer \& Mandl, 2005), most empirical studies on collaboration scripts do not discuss the role of the teacher in the collaboration. Many questions remain, such as whether or not it is realistic to expect students in vocational education to arrive at highlevel shared knowledge construction without the teacher's support. In response to these unanswered questions, our assumption is that the teacher does have a special role in 
empowering collaboration within 3D-game contexts (see the next section for a description of the 3D game).

Currently there is little knowledge about the teacher's role in 3D-game environments. Therefore, there is a need for empirical research concerning the teacher's role in future learning spaces. The empirical part of this study focuses on understanding collaborative learning by making sense of the collaboration processes in which the groups are engaged (Hmelo-Silver, 2003). This study is in line with Vosniadou, Ioannides, Dimitrakopoulou, and Papademetriou (2001), who argue that learning is greatly facilitated by promoting interactions with peers and, in particular, by the teacher acting in the 'zone of proximal development' (Vygotsky, 1978).

\section{Aim of the study}

This study aims to illustrate a scripted 3D-learning game ${ }^{2}$ for vocational education, and also to ask contextual questions in order to investigate teachers' real-time instructional activities for this game in terms of vocational knowledge construction. Firstly, based on our previous empirical evidence (Hämäläinen \& Oksanen, 2012), our hypothesis is that groups with real-time teacher instruction (Condition 1) will come up with more shared knowledge construction that can be considered productive (i.e., building knowledge on others' ideas and thoughts) than groups studying without real-time teacher instruction (Condition 2) in the scripted 3D-game setting. The assumption is that real-time teacher instructional activities are favourable for collaborative learning. Secondly, in case the above hypothesis finds empirical support, our aim is to seek further understanding of the role of teachers' instructional activities in empowering collaboration.

\section{Description of the 3D game}

The main concept behind the $3 \mathrm{D}$ game design is that it integrates challenges to trigger 
collaboration (with collaboration scripts) in a multiplayer game. The game story is based on authentic work-life situations. Therefore, eight work-life instructors were interviewed to identify the main shortcomings in terms of the know-how of students graduating from vocational education. (For a more detailed description, see Hämäläinen \& Oksanen, 2012.) Based on the interviews, inter-professional knowledge construction was identified as one of the key challenges in current vocational education, as students often have fairly good knowledge on their own profession (e.g., electricity supply), but in real work-life situations, their content knowledge needs to be integrated with that of other professions (e.g., electricity supply as part of construction). Thus, practicing interprofessional knowledge construction was identified as the main objective of the game. In order to practice inter-professional knowledge construction at vocational education, the game story consisted of various inter-professional tasks, and collaboration scripts were integrated within the story to support shared knowledge construction in solving the game's puzzles.

Next, we will introduce three scripted tasks about the Gamebridge -game (see Figure 1) and the intended knowledge construction activities. In the game, players are supposed to prepare for a rock festival. The following description illustrates the main ideas behind the collaboration scripts and the activity in the game.

[Please insert Figure 1 about here]

\section{Task 1: Gate - task scripted to trigger coordination between players}

In the first task (see Level 1, Figure 1), the aim is to practice coordination involving personal responsibility, dependency between players and control of an aggregate of individuals (Brown \& Campione, 1994). The multi-player goal is to enter the numbers of the code in the correct order in the combination lock. Each member of the group has 
only part of the information needed, and these parts have to be combined to solve the puzzle. At this point, the players are in the limited area next to the festival area behind the gate. When the players have successfully entered the code, they are able to move to the next level. The aim of this "rather easy" first task is to generate a positive resource interdependence (e.g., Johnson \& Johnson, 1994) among learners and force learners to start sharing knowledge with each other and to coordinate their actions in relation to each other.

\section{Task 2: Restaurant - task scripted to generate distributed expertise and mutual dependency between learners}

The second task (see Level 2, Figure 1) is more challenging and aims for distributed expertise, mutual dependency and integration of solo and group activities (Price Rogers, Stanton \& Smith, 2003). The goal is to serve 15 customers and 5 band members in a way that they leave satisfied from the restaurant. Players have their own predefined collaboration roles (De Wever, Schellens, Van Keer \& Valcke, 2008; Hoadley, 2010) that determine the challenges and actions the game sets and offers to each player. In practice, the first task is to reposition the fallen tables before the first customer comes in to have a meal. At a later phase, the receptionist invites customers into the restaurant. When a customer has settled at the table, the server is supposed to take his or her order and take it to the cook, who prepares the meal. After the meal is ready, the cook gives it to the server to serve. The customer then eats it and leaves the restaurant satisfied.

After 15 customers have been successfully served, the band comes into the restaurant for a meal. The band consists of five members, and four will be served the same way as normal customers. The lead singer differs from other band members, so that when the server is taking his order, the singer says something ambiguously, and thus the speech may not be understood. However, the server gets the information that 
the singer wants to have curry chicken. If the player who took the order does not react in any other way to the singer's message and serves him a curry chicken as normal, the singer refuses the meal and says he wants the meal he ordered. This loop goes on until the receptionist notices from the band's requirement list that the lead singer has a serious nut allergy, and he can't eat anything that contains nuts. Information about the allergy is available at reception. After having a curry chicken without nuts, the lead singer leaves the restaurant satisfied, the gate to the stage area opens, and the player moves to the next level.

Based on authentic work-life needs, the task includes additional tasks that hamper puzzle-solving. For example, the workman has his own tasks, which include, for example, the situation when the generator runs out of fuel and he has to refuel it. The receptionist also has to answer phone calls and act accordingly, in one case by inviting all players to listen to the producer's call. The two servers and cook have to report the number of prepared and served meals to the receptionist, who reports them to the producer. Missing a time limit in serving may cause, for example, an angry customer, who must then be reassured. In addition, randomly during the game, all players are supposed to search for an item lost in the festival area. Therefore, the key to this puzzle is not just performing individual tasks but integration and synchronization of all the tasks. Integration is also hampered by a resource hook, the fact that each player has a certain amount of energy available. To increase their energy, players have to have breaks and synchronization the breaks between the tasks. Running out of energy or failing in an individual task causes players to take a forced break. In the forced break situation, the players are moved to the break tent, and they are able to leave this area only when all the players are ready. The aim of the forced breaks is to rest from the otherwise fast-paced tasks and offer players a chance to rethink their working strategy. 


\section{Task 3: Stage - task scripted to guide the solving of socio-cognitive conflict}

The final task (see Level 3, Figure 1) aims to enter learners into a socio-cognitive conflict situation (Moscovici \& Doise 1994) and then guide them to solve the conflict.

The main goal of the puzzle is to identify each band member by combining received tips and organizing the band's equipment in the right place on the stage. Socio-cognitive conflict is created by giving different players different and partly contradictory information at the same time. In the beginning, the players have access to the stage area and notice roadies hanging around. The players are able to talk to the roadies, and when they do that, the roadies give the players hints about the appearance of the band's members. There are five roadies in the area, and each one gives his own tips. All players also have their own tips, so in total the players are able to have 25 tips.

There are boxes on the stage, and the players are able to change the owner of each pile of boxes. There are, overall, eight piles of boxes. Five belong to the actual band members, and the rest belong to the warm-up band. One by one, the players are supposed to identify the band members according to the tips and pictures on the boxes and recognize which of the piles of boxes belong to the warm-up band. However, boxes cannot be placed correctly without proper coordination and knowledge-sharing, and the conflicting information challenges players to combine and re-examine their existing knowledge in order to achieve a successful completion. After arranging all of the boxes in the right order, the players have gone through the entire game.

\section{Method}

\section{Participants, context, and data collection}

The empirical part of this study was conducted in an authentic classroom setting. The goal was to capture the required data from different collaboration situations by one 
video camera and a recording system, both used in each setting. The camera was placed to film video feed from a virtual camera from an observer's point of view (inside the game play). Related to that, this observer's non-player display was placed inside the 3D environment, handled by one of the researchers. In practice, non-player display enabled following the game play, but participants did not discern recording.

The data were collected from fall 2010 to spring 2011. Altogether, 27 vocational students between the ages of 16 and 18 and three teachers took part in the study, making up six groups of five people ( $\mathrm{N}=30,23$ males, 7 females) (the names used are pseudonyms). The students were randomly divided into four groups while the teachers were placed in different groups by conscious choice. The goal behind these allocations was to vary the working conditions to the extent possible. All in all, the data collection phase consisted of a two-to-three hour working period in a scripted 3D-environment in the College of Jyväskylä in Finland. The participants were isolated from one another physically, and cubicles were arranged in a way that prevented outside disturbances. During the study period, the participants could communicate only through the VoIP speech system.

In the empirical study, three groups with and three groups without real-time teacher instruction (Condition/Setting 1 vs. Condition/Setting 2) solved scripted puzzles in a 3D learning game. No specific instructions were given to the participants before the working period; however, the teachers were told in advance that the game aimed at enhancing the students' future working skills. Moreover, the goal was to study the teachers' abilities in empowering collaboration in a 3D setting. According to RuizPrimo, Figueroa and Gluckman (2011), in a collaborative process it necessary to look at the dialogue between all the participants. In this study, the role of the teacher was to collaborate with students during the game play. In practice, this meant that the teacher 
did not only guide and facilitate but also participate by joining the students shared knowledge construction (see Hämäläinen \& Vähäsantanen, 2011). In Condition 1 of the present study, the students and the teacher thus worked together to identify problems and methods of finding solutions (Sawyer, 2004). In Condition 2, the students solved the puzzles themselves. These conditions were used to meet the authentic needs surfacing in the vocational context: to empirically examine whether and/or how the realtime participation of teachers may empower collaboration.

The group discussions were videotaped and recorded straight from the VoIP speech system using the software "Audacity". These resources were used to compare collaboration processes between different scripted 3D learning conditions (Setting 1 with and Setting 2 without real-time teacher instruction) in order to uncover the main differences between these processes.

\section{Data analysis}

In the data analysis, the data were revised and a content analysis was done on the knowledge construction process comparing the two research settings (Condition 1 and

2). Firstly, all the video data were transcribed after the empirical study, including a total of 13,472 utterances from six groups. Also, the videos were watched and transcribed discussion entries were read through several times by two researches (authors) to familiarize ourselves with data. Of the full 13,472 utterances, 13,140 were categorized to include activities of shared knowledge construction, whereas some were excluded as unclear (i.e. due to overlapping speech acts or laughing).

After the first categorization, another 5004 of the full 13,140 utterances were classified as having the teacher as an active group member. Furthermore, 8136 utterances were marked as discussion entries of mere student groups. This categorization divided the analysis of knowledge construction in two. This was 
followed by a content analysis as studies indicate that quantitative and qualitative content analyses are beneficial for understanding group processes and their contextual nature (De Wever et al., 2006). Thus, we aimed to understand how knowledge construction was jointly built on others' ideas and thoughts. In order to evaluate knowledge construction and the ways in which the two collaboration settings differed, quantitative and qualitative content analyses were conducted ${ }^{3}$ (Berelson, 1952). The discussions were analysed in two phases. The first step was to divide the discussions into six main categories, based on the functional roles in the participants' utterances. In practice, 13,140 utterances were first divided in six main categories: 1) providing knowledge, 2) contextual questions, 3) shared problem solving, 4) management of interaction, 5) summing up/discovering a solution and 6) other inputs. In the next level of the analysis, the goal was to gain deeper understanding of the knowledge construction processes. More detailed exchanges between the group members were examined in depth to find qualitative differences in the knowledge construction processes. Specifically, the utterances were sorted into 25 data-driven subcategories (e.g., Beers, Boshuizen, Kirschner, \& Gisselaers 2007) according to more detailed functions of interaction. (Related to this, this study was a follow-up to our previous empirical study using the same categorization of knowledge construction processes. Therefore, for a detailed description of the analysis, see Hämäläinen \& Oksanen, 2012).

\section{Results}

\section{Descriptive results}

In total, 13,140 utterances were analysed with the content analysis (see Table 1 for an overview of the descriptive results). The conditions involving studying with real-time teacher instruction included 5004 utterances while student groups studying without real- 
time teacher instruction included 8136 utterances. In both conditions, interaction activities were mediated by a scripted 3D game and all the groups followed the scripted task order during the game play. However, there were differences between these two conditions in their shared knowledge construction during the game play. As illustrated

in Table 1, in both conditions utterances involving shared problem solving, management of interactions, and summing up or discovering a solution comprised a similar percentage of the discussions. The main differences between the conditions studying with and without real-time teacher instruction involved how members of the group provided knowledge, asked contextual questions and engaged in other forms of conversation when solving game tasks.

[Please insert Table 1 about here]

\section{Results for hypothesis 1}

As we can see from Table 1, groups with real-time teacher instruction (Condition 1) used more productive knowledge construction activities by providing knowledge (Condition 1=29.3\%, Condition 2=23.3\%) (Example of providing knowledge; "The singer of the band is allergic to nuts") and asking contextual questions (Example of contextual question: "What is he complaining about?") (Condition $1=17.3 \%$, Condition $2=12.1 \%$ ) than groups studying without real-time teacher instruction (Condition 2$)$ that used $32.6 \%$ of their utterances for other discussions in the scripted 3D-game setting. Thus, this empirical finding supports the assumption that real-time teacher instructional activity is more favourable to collaborative knowledge construction than groups studying without real-time teacher instruction. As the content analysis revealed differences in how groups explained their own situations, next empirical examples 1 and 2 will shed the light on the role of the teacher in empowering collaboration. 


\section{Teachers' instructional activity}

Our previous pre-study focused on the differences in off-task discussions in these two different settings, illustrating how teachers' real-time instructional activity of teacher was beneficial for collaboration. In this study, further data (to double the number of discussions) was collected and analysed to further seek and understand teachers' instructional activities. Two main differences were found related to how groups with real-time teacher instruction were more productive in their knowledge construction activities. Firstly, participants in Condition 1 used $12.1 \%$ of their utterances to explain their own situation, while those in Condition 2 used 6.2\%. Secondly, in Condition 1, asking for specifying questions was used more actively ( $12 \%$ of utterances compared to $8.8 \%$ in condition 2 ). In other words, collaboration in the groups with real-time teacher instruction focuses more on asking specifying questions and explaining one's activities. In the following section, we will illustrate, with empirical examples, teachers' instructional activities related to explaining one's situation and asking specifying questions.

Empirical examples 1 and 2 of the same event illustrate the difference in the use of explaining one's activities in the scripted task of "the restaurant". Specifically, the aim of the task was to create a learning situation based on distributed expertise, mutual dependency and integration of solo and group activities (Price et al., 2003). In practice, each of the members has complimentary inter-professional roles that require working together as a team. The group has to solve a problem in which a band member has a nut allergy but he is ordering a portion from the waitress that usually includes nuts (for more detail see description of the game level 2). Thus, the group needs to work as a team to determine what is wrong with the portion and serve the correct one without nuts. These two corresponding events in different learning settings (with and without 
real-time teacher instruction) (Examples 1 and 2) illustrate the difference in the use of explaining one's own activities.

Example 1: Knowledge construction that included explaining one's own activities as a part of solving an inter-professional task.

Jack: Where is my order? [Jack provides knowledge by bringing in the information from the environment] (Providing knowledge; New information (Pk;Ni))

Mike: Well, should we just make something for this guy? (Contextual questions; Opinion $(\mathrm{Cq} ; \mathrm{O}))$

Jack: Let's do it in random. (Management of interaction; Group organization (Mi;Go))

Laughter

Jan: Let's try it. (Management of interaction; Group organization)

Mike: No, 'cause I don't have any foodorder, I can't do anything. (Providing knowledge; Explaining one's own situation (Pk;Eos))

Mike: Well now you have a chicken curry. (Providing knowledge; Explaining one's own situation)

Jan: That Jack character looks a little like that talking head on MTV3. (Other input; Related to task $(O i ; R t))$

Mike: Now is the chicken curry ready. (Providing knowledge; Explaining one's own situation)

Teacher: Yes. (Other input; Related to task) [1] 
Mike: There, I have to go and take a break now. (Providing knowledge; Explaining

one's own situation)

Jack: Now he wants a new meal. (Providing knowledge; New information)

Teacher: What is he complaining about? (Contextual questions; Specifying $(C q ; S)$ ) [2]

Mike: Oh hell. (Other Input - related to task)

Teacher: This is difficult this purple fellow. (Providing knowledge; New information)

[3]

Jack: He wants chicken curry again for a change. (Providing knowledge; New

information)

Mike: But I just made it, didn't I. (Providing knowledge; Explaining one's own situation)

Jack: He's hungry. (Other input; Related to task)

Jack: The hippie can't decide. (Other input; Related to task)

Mike: Ok, Now I'm coming there to the cooking place. (Providing knowledge;

Explaining one's own situation)

Teacher: It wasn't good enough for him even though I brought it. (Providing

knowledge; Explaining one's own situation) [4]

Mike: So. (Other input; Related to task)

Mike: Well... (Other input; Related to task)

Mike: What this ... (Other input; Related to task) 
Jack: Yeah. (Other input; Related to task)

Mike: Oh darn. (Other input; Related to task)

Jack: Fetch that jerry can and burn down the whole tent. (Providing knowledge; Piece of advice - contextual $(P k ; P a c))$

Laughter

Jan: The singer of the band is allergic to nuts. (Providing knowledge; New information)

Jack: What? (Contextual questions; Specifying)

Jan: There are no nuts in that food, are there? (Management of interaction;

Organizational questions $(\mathrm{Mi} ; \mathrm{Oq}))$

Mike: Yes there are in that chicken curry. (Shared problem solving; Answers (Sps;An))

Mike: Now this has to be reset again. (Management of interaction; Planning upcoming $\operatorname{activity}(\mathrm{Mi} ; \mathrm{Pua}))$

Jan: What is this rider (?) here on the table? (Contextual questions; New openings $(\mathrm{Cq} ; \mathrm{No})$

Jan: Two times festivalspecial, two times chicken curry and one vegetable....towels to the backstage, mineral water, the vocalist is allergic to nuts. (Providing knowledge; New information)

Mike: Now I have the chicken curry, but it contains nuts. Do we serve it anyway? (Contextual questions; reasoning $(C q ; R)$ )

Teacher: Yes, I'm able to take it, if you like (Providing knowledge; Explaining own 
situation) [5]

Mike: Let's see what happens ..(Management of interaction; Planning upcoming activity)

Teacher: He will go wild...or, he will die. (Other input - related to task) [6]

Laughter

Jack: Bah, well, a new order (Providing knowledge; New information)

Mike Well I'll do it then without it when you bring me the order... If it can be done...

(Providing knowledge; Explaining one's own situation)

Jack: And I need yet another chicken curry. (Providing knowledge; Explaining own situation)

Mike: ...without the darned nuts (Providing knowledge; Piece of advice-contextual)

Mike: Well, apparently it can be done. (Providing knowledge; Explaining one's own situation)

Teacher: I have to take a break again. (Providing knowledge; Explaining own situation)

Mike: Ok now here is. (Providing knowledge; Explaining own situation)

Mike: There you go. (Providing knowledge; Explaining own situation)

Laughter

Jan: The singer has got a severe food allergy. (Summing-up

/ discovering a solution; Based on group activities (Sds;Bga)) 
Jack: Well he seems quite happy anyway. (Shared problem solving; Agrees (Sps;Ag)

Jack: Now he's gone. (Providing knowledge; New information)

Researcher's interpretation: In Example 1, content analysis reveals that in condition involving the teacher's real-time instructional activity, knowledge construction included explaining one's own activities as a part of solving inter-professional tasks. In the above example, explaining own activities in shared knowledge construction was shown in communication, as Jack began by providing new information that the customer is waiting for his order. Mike responded with a contextual question that included his opinion that they should serve him (as a group). Next, Jack began managing the group work and Jan continued that. Then Mike explained his situation that he could not proceed as he did not have any orders. As a result, he received an order from his team member and continued explaining his situation. Then, Jan commented on the appearance of the avatar. Mike turned the debate back to the problem by explaining his situation again. Then, the teacher followed the activities. Mike gave the portion to the waitress and explained that he needed to go on a break. Then, Jack introduced the new information that the customer wanted a new portion. The teacher asked what the customer was complaining about. Mike gave a frustrated comment related to the task, as they were not proceeding well. The teacher provided knowledge that this was a challenging part of the task, but did not provide ready-made solutions. Jack continued solving the problem by stating that the customer wanted a new portion. Mike explained that he just completed the same order. Jack then made a joke, admitting that the customer must have been quite hungry or could not decide what he wanted. Mike continues solving the situation and explains that he is coming back to the kitchen. The teacher explains that he also tried to serve the portion but was unsuccessful. Then, Mike provided an accommodative comment and two other small comments related to the task, 
followed by Jack, and Mike. Jack then began to get nervous and suggested they should burn the whole tent. (Everyone laughs). This was followed by Jan bringing in a new, important piece of information that the singer had a nut allergy. Jack asked contextual questions as he wanted to be sure. Then, Jan asked a question that was related to how they were making the portion (if it includes nuts). Mike continued solving the problem and reported that the portion included nuts in its current form. Subsequently, he realized that they needed to start again and made plans accordingly. Next, Jan asked a question that led their group work in a new direction (a bit later) and introduced new information after the question. Related to that, Mike asked if they would serve the portion that included the nuts for the singer that is now ready. The teacher stated that the environment would permit him to take the portion to the customer. Mike suggested that they should serve it and see what happens. The teacher commented about the worst case scenarios. (Everyone laughs). Then, Jack informed the group that there was a new order again. Mike explained that he would make a portion without nuts if possible. Jack continued by explaining the he needed curry chicken. Mike supplemented that, without nuts this time and noted that it was possible for him to make a portion without nuts. The teacher then told him that he had to take a break (in the task). Mike explained that his part was completed. Jan summed up the situation based on the previous activities. Jack agreed and provided knowledge that the customer finally left.

The above example reveals that each of the members contributed to solving a portion of the task and had personal responsibility related to how the team was able to solve the task. Thus, we can see that problem solving with real-time teacher instruction can be called productive knowledge construction, as members develop processes and ways to explain their own situation in inter-professional task solving that lead to the shared knowledge built on others' ideas and thoughts (see also Arvaja et al. 2007). 
Added to this, knowledge construction was based on reciprocal interaction between the participants (including the teacher). The above example also shows that the members had a shared goal (to serve the customer) which they collectively strove to achieve. The role of the teacher was to monitor outbound activity of the group itself. In practice, this was done by channeling and focusing learning processes (see Pea 2004), instead of providing direct advices or correct answers. The above example illuminates five different ways that the teacher used (through his utterances) to facilitate shared knowledge construction. First, the teacher follows shared problem solving [1]. Second as, the group faced a problem, the teacher facilitated shared knowledge construction by asking contextual questions [2]. Third, as the question itself did not provide enough support to solve a problem the teacher provided knowledge that this was a challenging part of the task, but did not offer a ready-made solution [3]. Fourth, after some time, the teacher used his own experience to explain the problem as grounds for the group to interpret problem and formulate possibilities for solving it [4],[5]. Finally, to empower the learning discourse, the teacher used real-life based scenario about what might happen in the worst case to highlight the need for shared knowledge construction [6]. This empirical example illustrates the teacher's ability to apply learning methods that require students to formulate hypothesis, interpret context, provide explanations, and describe observations (Hämäläinen \& Vähäsantanen 2011). As we can see, the teacher's instructional activities were grounded by intention to facilitate, channel, and monitor shared knowledge construction while he left the responsibility of solving the task to the students. Moreover, the reaction of students in the teacher's real-life based scenario [6] indicates an emotionally safe atmosphere of knowledge construction (see Eteläpelto \& Lahti 2008). Thus, the teacher's role as a fellow collaborator was to activate productive knowledge construction processes, such as encouraging students to formulate 
hypotheses, providing explanations, conceptualizing his own experiences, and describing observations (see also Hämäläinen \& Vähäsantanen 2011).

Next, we will examine learning without real-time teacher instruction in a scripted setting (Example 2). We see that, since the group did not actively explain their own situations in the inter-professional task solving process, they struggled to move forward with the task. Furthermore, the scripted environment forced the group to stop and change directions several times. However, despite the scripted environment, students were not able to explain their own situation in a way that would have led to productive knowledge construction processes without the teacher's assistance.

Example 2: Obscure problem solving in an inter-professional task

Joel: Everybody takes the break at the same time. (Management of interaction; Group organization)

Tom: well yes it is.(Other input - related to task)

Sam: Take a break (Management of Interaction; Group organization)

Sam: Everything is getting blurred, I'll fall down in front of the tent (Providing knowledge; Explaining one's own situation)

[18 utterances of excluded discussion]

Joel: I have got still one order (Shared problem solving; Continue one's work $(\operatorname{Sps} ; \mathrm{Cow}))$

Tom: Don't bring me any new orders, the generator is not working (Management of interaction; Group organization) 
Tom: Now this meal will not be ready (Providing knowledge; New information)

[47 utterances of excluded discussion]

Tom: I did give you an order Joel (Providing knowledge; Explaining one's own situation)

Joel: Oh, to me? (Contextual questions; Specifying)

Tom: Yes (Shared problem solving; Answers)

Joel: I see (Shared problem solving; Continues one's work)

[89 utterances of excluded discussion]

Jens: Well when you don't give him any food so he'll go mad (Shared problem solving;

Reasoning $(\operatorname{Sps} ; R))$

Jens: Smash his face in (Providing knowledge; Piece of advice - contextual)

Jens: Damn (Other input - related to task)

Tom: Bring me an order, bring me an order (Providing knowledge; Piece of advicecontextual)

[11 utterances of excluded discussion]

Joel: Where's my order (Providing knowledge; New information)

[66 utterances of excluded discussion]

Sam: Well, one order already came to you (Providing knowledge; New information)

Jens: They want some mineral water and the singer of the band has a nut allergy 
(Providing knowledge; New information)

Jens: They want a hammock and they want their food soon (Providing knowledge; New information)

Tom: Out (Providing knowledge; New information)

Sam: I did not order this meal (Providing knowledge; New information)

[8 utterances of excluded discussion]

Tom: Serve the order, serve the order Sam (Providing knowledge; Piece of advicecontextual)

Tom: Take it to that guy somewhere there (Providing knowledge; Piece of advicecontextual)

Tom: He's there that red one (Providing knowledge; Piece of advice - contextual)

Jens: ....that nut...(Shared problem solving; Disagrees $(\operatorname{Sps} ; D))$

[67 utterances of excluded discussion]

Tom: chicken curry (Providing knowledge; New information)

Sam: He didn't want that meal (Providing knowledge; New information)

[31 utterances of excluded discussion]

Jens: That one guy won't eat nuts.(Providing knowledge; New information)

Jens: I don't know which one of them, draw lots (Providing knowledge; New information) 
Joel: For me it seems like it's not coming (Providing knowledge; Explaining one's own situation)

Tom: Oh fuck (Other input - related to task)

Jens: No it's the singer but which one of them is the singer? (Providing knowledge; New information)

[28 utterances of excluded discussion]

Jens: So no nuts for him (Shared problem solving; Continue one's work)

Tom: Well I already put the nuts in there (Providing knowledge; Explaining one's own situation)

[63 utterances of excluded discussion]

Tom: One chicken curry must be made without nuts.(Shared problem solving; Answers)

Sam: Oh (Shared problem solving; Agrees)

Researcher's interpretation of Example 2: The first time the group encountered the problem, no one mentioned it; as we can see, Joel began to manage group organization, Tom commented on another issue related to the task, Sam continued engaging in organizational activities and Sam explaining his situation. Next, there were 18 utterances of discussion related to other topics (that were excluded from the example for brevity). Then, they returned back to solving the problem, as Joel kept track of the next order. However, Tom was already in trouble; he admitted that he could not take any more orders, as the generator was no longer working and it was not possible to make the food. Then, the group focused on another topic for 47 utterances and returned to the 
problem again. Tom explained that he gave Joel the order. However, Joel had not noticed it and queried him. Tom agreed and Joel confirmed that he understood. Subsequently, the team again focused on other issues (89 utterances). Then, Jens returned to the fact that the singer had not yet received food, gave contextual but irrelevant advice, and commented about the failure. Next, Tom continued the topic at hand by hurrying Sam up (11 utterances of excluded discussion). Following this, Joel informed the group that the customer was still waiting, and repeated the customer's question. Then, the group moved to other topic for 66 utterances and left the problem unsolved. After a while, the environment forced the team to get back to the problem and Sam noted that the order had to be delivered. Jens noticed the nut allergy information and other requirements. Tom complimented this and Sam noted that the customer was complaining (8 utterances of excluded discussion). Then, Tom gave very unclear pieces of advice regarding who they should serve and Jens tried to get back to the fact that the portion should not include nuts. However, despite the fact that Jens mentioned the solution, the team moved to other topics for 67 utterances. Then, Tom returned to the issue that they should serve the singer and Sam stated that the singer did not want the served portion. After 31 utterances (excluded from the example) Jens repeated that the singer did not eat nuts and asked who the singer was. Joel explained his situation, Tom cursed the problem, and Jens began to realize that the problems might be related to the singer and his nut allergy. Then there were 28 utterances excluded from the discussion that were related to the topic but did not lead to the solution. Finally, Jens powerfully repeated that there had to be no nuts for the singer and Tom explained that he already added the nuts in the portion. Despite the fact that they now had solution, it took 63 utterances to ultimately solve the task. In the end, Tom stated that they had to make portion without nuts and Sam agreed. 
This example highlights several problems in the knowledge construction process. For one, it illustrates that none of the group members made the shared goal explicit (to serve the customer). As can be seen from the significant number of utterances, the students struggled to focus and solve the task, and the scripted environment forced them to solve the task before they were able to proceed. To compound their dilemma, the team tried to avoid the task several times by moving the other topics. The fact that the environment forced them to alter their activities (e.g. viewing changes as unclear and the generator was not working) demonstrates how members of the team were not able to listen to each other, explain their own activities, or give clear instructions or proposals to resolve the problem for other team members. As can also be seen, the discussion proceeded obscurely and although their knowledge was partly built on others' ideas (as the environment itself imposed upon them) the team work was neither clearly goal-oriented nor truly reciprocal. The main reasons for these problems were that learners were neither able to develop ways to explain their own situation that inter-professional tasks require nor to build on knowledge based on others' ideas. This is evident in the example above, as no one from the group listened to Jens although he had knowledge that was essential for solving the problem and he tried to share it several times.

When we compare these two different learning settings (with and without realtime teacher instruction) we see the discrepancies in terms of how the knowledge was built on others' ideas and thoughts. In practice, groups who had teachers' real-time instructional activity developed better complimentary roles of the participants in how members of the group asked contextual questions and provided knowledge. Example 1 illustrates the role of teachers in supporting collaboration. It is clear that the teacher did not provide ready-made solutions for the group. Rather, the teacher developed different 
ways to empower collaboration processes within the group by feeding groups shared knowledge construction, for example, by asking questions and highlighting real-life scenarios to encourage group in formulating hypotheses, providing explanations, conceptualizing his/her own experiences, giving hints and describing observations. In contrast, in setting 2, students studying without real-time teacher instruction had more difficulty creating shared goals, describing (explaining) what was happening, and proposing solutions for the problems.

\section{Discussion}

Recent studies have shown that games can, at their best, generate high-level learning processes through collaborative activities in new virtual environments (Whitton, 2010). Adding the demonstrative value of virtual environments, games can be seen as one great future innovation. Since 2004, our series of design-based studies has focused on designing 3D game environments as a response to future learning needs in the vocational education context. Results from these studies have been promising, and it has been noted that games clearly add value to the practice of vocational skills (Hämäläinen, 2008; Hämäläinen, 2011; Hämäläinen \& Oksanen, 2012). On one hand, these studies have shown that scripted virtual games can generate high-level learning. On the other hand, the teacher's role in these evolving learning environments has become problematized (Hämäläinen \& Oksanen, 2012). The findings also suggest that the processes and results of collaborative learning are highly contextual when the students work by themselves in a virtual environment (Arvaja, 2012). Therefore, it seems that one central challenge in future research will be to collect systematic data about the teacher's role in enhancing and supporting collaborative activities in the technological environment (see Van de Pol, Volman, \& Beishuizen, 2010). In the light of the results produced in this study, it is possible for teachers to help learners in 
vocational education to discover higher forms of collaborative activities. This has interesting implications for the future as teachers' role in collaboration in $3 \mathrm{D}$ settings is not often studied.

Comparing the differences between studying with and without real-time teacher instruction resulted in differences in shared knowledge construction processes related to enhancing inter-professional skills. Our study showed that the teacher's participation in collaborative work helped different groups to develop productive ways of providing knowledge and asking contextual questions. The teacher played a significant role, especially in terms of how group members managed to explain their own situations and ask clarifying questions that led to more explaining. This observation is crucial because the ability to explain one's actions is a central vocational skill for one's future work life. Additionally, previous literature has found providing explanations to be more powerful than other kinds of participation in collaboration activities (Bargh \& Schul, 1980; King, 1992). In line with this notion, Webb and others (2008) argue that it is possible for the teacher to support high-level understanding by inviting students to explain and elaborate on their explanations. Thus, a skilled teacher will collaborate with his/her students so they learn to correct misconceptions and verbalize the correct explanation when their initial answers or strategies are incorrect. In this study, analyzing teacher activities in depth showed that the teacher's role when working in a 3D game environment is not to give the students the correct answers. Instead, shared teacher and student activities in the game space supported the view that the teacher's role should serve to enhance collaborative activity. As shown in example 1, the teacher used different strategies to empower collaboration, such as asking contextual questions, providing knowledge about a challenging part of the task, and using his/her own experience to explain the 
problem as grounds for the group to interpret it and formulate possible solutions or reallife scenarios about what might happen in real work-life situations.

The results of this study are intriguing when considering the design of future game environments. For one, it seems that teachers have diverse opportunities to support collaborative processes in these kinds of environments. However, this active role will, in fact, pose challenges for designing virtual game spaces. Moreover, in the present study, each teacher participated in shared group work, which tied his/her working hours to working with the group. Thus, a future challenge will be to develop virtual spaces that produce knowledge about how collaboration proceeds while still enabling the teacher to monitor several game groups' activities simultaneously. With the help of these functions, the teacher will also be able to help the groups when necessary, for example by providing guidance about how the students could resolve discrepant answers by listening to and trying to understand each other's explanations, and not accepting each other's answers unless they are able to explain why they are correct (see Webb et al., 2008).

In conclusion, game environments can offer varied opportunities for collaborative learning. From the perspective of designing future learning spaces, studies should thus focus systematically on technological developments and on the teacher's role in supporting collaborative activities. As a result, opportunities for high-level learning in virtual game environments will increase.

\section{Acknowledgements}

This research was supported by the Academy of Finland (Project n:o 258659). The development of the 3D environment was supported by the EU Structural Funds and nationally

by the State Provincial Office of Western Finland from the administrative sector of the Ministry of Education. Special thanks to Birgitta Mannila, Ludocraft Ltd and Jyväskylä College. 


\section{Notes}

1. This article is in line with the notion of Arvaja, Salovaara, Häkkinen and Järvelä (2007), according to whom collaboration is defined as a shared knowledge construction in which it is not enough that participants cumulatively share knowledge together (Mercer, 1996), but where the knowledge construction needs to be jointly built on others' ideas and thoughts (Mercer, 2010). (For more detailed see, Hämäläinen \& Vähäsantanen, 2011).

2. The development of the Gamebridge -game is a joint effort among three parties, the Institute for Educational Research at the University of Jyväskylä, Jyväskylä College, and the LudoCraft Ltd.

3. Transcripts were coded independently by both authors and one trained coder. To determine the level of correspondence among these three coders, the reliability coefficient Krippendorff's alpha was calculated. Krippendorff's alpha (a) inter-rater reliability coefficients were a $=0.949$ for six theorybased main categories and $\mathrm{a}=0.943$ for data-driven subcategories. Both values were situated within the classification of high reliability ( $\mathrm{a} \geq .800$ ) (Krippendorff, 2004, p. 241; Lombard, Snyder-Duch, $\&$ Bracken, 2002). However, it has to be noted that strong agreement is influenced by joint meetings during the coding process and the fact that two of the coders (authors) have several years' background in developing this method to analyze collaborative knowledge construction in 3D game settings.

\section{References}

Arvaja, M. (2012). Personal and shared experiences as resources for meaning making in a philosophy of science course. International Journal of Computer-Supported Collaborative Learning.

Arvaja, M., Salovaara, H., Häkkinen, P., \& Järvelä, S. (2007). Combining individual and group-level perspectives for studying collaborative knowledge construction in context. Learning and Instruction, 17(4), 448-459.

Bagley, E. \& Shaffer, D.W. (2009). When people get in the way: Promoting civic thinking through epistemic gameplay. International Journal of Gaming and Computer-mediated Simulations, 1(1), 36-52.

Baker, M. (2010, September). Approaches to understanding students' dialogues: articulating multiple modes of interaction. Keynote speaker lecture presented to an EARLI SIG 17 Qualitative and Quantitative Approaches to Learning and Instruction. Jena, Germany.

Bargh, J. A., \& Schul, Y. (1980). On the cognitive benefit of teaching. Journal of Educational Psychology, 72(5), 593-604. 
Beers, P.J., Boshuizen, H.P.A., Kirschner, P.A., \& Gijselaers, W.H. (2007). The analysis of negotiation of common ground in CSCL. Learning \& Instruction, $17(4), 427-435$.

Berelson, B. (1952). Content analysis in communication research. Glencoe, IL: Free Press.

Brown, A. \& Campione, J. (1994). Guided discovery in a community of learners. In K. McGilly, Classroom lessons: integrating cognitive theory and classroom practice (pp. 227-270). Cambridge, MA: MIT Press.

Chi, M. (1997). Quantifying qualitative analysis of verbal data: A practical guide. Journal of the Learning Sciences, 6(3), 271-315.

Connolly, T., Boyle, E., MacArthur, E., Hainey, T. \& Boyle, J. (2012, In press). A systematic literature review of empirical evidence on computer games and serious games. Computers and Education. DOI: 10.1016/j.compedu.2012.03.004

De Jong, T. (2006). Computer simulations: Technological advances in inquiry learning, Science, 28, 532-533 DOI: 10.1126/science.1127750

de Jong, T., \& van Joolingen, W. R. (1998). Scientific discovery learning with computer simulations of conceptual domains. Review of Educational Research, 68(2), $179-201$.

De Wever, B., Schellens, T., Van Keer, H., \& Valcke, M. (2008). Structuring asynchronous discussion groups by introducing roles: Do students act in line with assigned roles? Small Group Research, 39(6), 770-794.

De Wever, B., Schellens, T., Valcke, M., \& Van Keer, H. (2006). Content analysis schemes to analyze transcripts of online asynchronous discussion groups: A review, Computers \& Education, 46(1), 6-28.

Eteläpelto, A., \& Lahti, J. (2008). The resources and obstacles of creative collaboration in long-term learning community. Thinking Skills and Creativity, 3(3), 226-240.

Gee, J.P. (2007). Good video games + good learning. Collected essays on video Games, learning and literacy. New York: Peter Lang Publishing.

Hmelo-Silver, C.E. (2003). Analyzing collaborative knowledge construction multiple methods for integrated understanding. Computers \& Education, 41(4), 397-420.

Hämäläinen, R. (2011). Using a game environment to foster collaborative learning: a design-based study. Technology, Pedagogy and Education, 20(1), (61 - 78).

Hämäläinen, R. (2008). Designing and evaluating collaboration in a virtual game environment for vocational learning. Computers \& Education, 50(1), (98-109). 
Hämäläinen, R., \& Oksanen, K. (2012). Challenge Of Supporting Vocational Learning: Empowering Collaboration In A Scripted 3D Game - How Does Teachers' Real-Time Orchestration Make A Difference? Computers \& Education, 59(2), (281-293).

Hämäläinen, R., \& Vähäsantanen, K. (2011). Theoretical and pedagogical perspectives on orchestrating creativity and collaborative learning. Educational Research Review, 6(3), 169-184.

Hoadley, C., (2010). Roles, design, and the nature of CSCL. Computers in Human Behavior, 26(4), 551-555.

Johnson, D.W., \& Johnson, R.T. (1994). Learning together. In S. Sharan, Handbook of cooperative learning methods (pp. 51-64). Westport: Greenwood Press.

King, A. (1992). Facilitating elaborative learning through guided student-generated questioning. Educational Psychologist, 27(1), 111-126.

Krippendorff, K. (2004). Content analysis: An introduction to its methodology (2nd ed.). Thousand Oaks, CA: Sage.

Kobbe, L., Weinberger, A., Dillenbourg, P., Harrer, A., Hämäläinen, R., \& Häkkinen, P. (2007). Specifying computer-supported collaboration scripts. International Journal of Computer-Supported Collaborative Learning, 2(2/3), 211-224.

Lindley, C.A., Nacke, L. \& Sennersten, C.C. (2008). Dissecting play - investigating the cognitive and emotional motivations and affects of computer gameplay. In Proceeding of CGAMES (pp. 9-16). Wolverhampton: University of Wolverhampton.

Lombard, M., Snyder-Duch, J.,\& Bracken, C. C. (2002). Content analysis in mass communication: Assessment and reporting of intercoder reliability. Human Communication Research, 28(4), 587-604.

Mercer, N. (1996). The quality of talk in children's collaborative activity in classroom. Learning and Instruction, 6(4), 359-377.

Mercer, N. (2010). The analysis of classroom talk: Methods and methodologies. The British Journal of Educational Psychology, 80, 1-14.

Moscovici, S., \& Doise, W. (1994). Conflict and consensus: a general theory of collective decisions. London: Sage Publications.

Papastergiou, M. (2009). Online computer games as collaborative learning environments: prospects and challenges for tertiary education. Journal of Educational Technology Systems, 37(1), 19-38. 
Pea, R.D. (2004). The social and technological dimensions of scaffolding and related theoretical concepts for learning, education, and human activity. Journal of the Learning Sciences, 13(3), 423-451.

Prensky, M. (2007). Digital game-based learning. New York: McGraw-Hill.

Price, S., Rogers, Y., Stanton, D., \& Smith, H. (2003). A new conceptual framework for CSCL: supporting diverse forms of reflection through multiple interactions. In B. Wasson, S. Ludvigsen, U. Hoppe, Designing for change in networked learning environments. Proceedings of the International Conference on Computer Support for Collaborative Learning. (pp. 513 - 523). Bergen: InterMedia.

Rieber, L.P. \& Noah, P. (2008). Games, simulations, and visual metaphors in education: antagonism between enjoyment and learning. Educational Media International, 45(2), 77-92.

Ruiz-Primo, M.A., Figueroa, M., \& Gluckman, M. (2011, April). Testing a premise of inquiry based science instruction: exploring small group processes and its link to student learning. Paper presented at the AERA meeting, 2011.

Rutten, N., van Joolingen, W. \& van der Veen, J. (2012). The learning effects of computer simulations in science education. Computers and Education 58(1). 136-153.

Sawyer, R.K. (2004). Creative teaching: Collaborative discussion as disciplined improvisation. Educational Researcher, 33(3), 12-20.

Silseth, K. (2012). The multivoicedness of game play: Exploring the unfolding of a student's learning trajectory in a gaming context at school. International Journal of Computer-Supported Collaborative Learning, 7(1), 63-84.

Van de Pol, J., Volman, M., \& Beishuizen, J. (2010). Scaffolding in teacher-student interaction: A decade of research. Educational Psychology Review, 22(3), 271297.

Vandercruysse, S., Vandewaetere, M., Clarebout, G. (2011, August). Game-based learning: A review on the effectiveness of educational games. Paper presented at an Earli 2011. Exeter.

Villalta, M., Gajardo, I., Nussbaum, M., Andreu, J.J., Echeverría, A., \& Plass, J.L., (2011). Design guidelines for classroom multiplayer presential games (CMPG), Computers \& Education, 57(3), 2039-2053. 
Vosniadou, S.I., Ioannides, C., Dimitrakopoulou, A., \& Papademetriou, E. (2001).

Designing learning environments to promote conceptual change in science. Learning and Instruction, 11(4), 281-419.

Vygotsky, L. (1978). Mind and society. Cambridge, MA: Harvard University Press.

Webb, N. M., Franke, M. L., Ing, M., Chan, A., De, T., Freund, D., et al. (2008). The role of teacher instructional practices in student collaboration. Contemporary Educational Psychology, 33(3), 360-381.

Weinberger, A., Ertl, B., Fischer, F., \& Mandl, H. (2005). Epistemic and social scripts in computer-supported collaborative learning. Instructional Science, 33(1), 1-30.

Whitton, N. (2010). Learning with digital games. A practical guide to engaging students in higher education. Routledge: New York. 
Table 1. Main differences between settings 1 and 2 .

\begin{tabular}{|c|c|c|}
\hline Theory-based main categories & $\begin{array}{l}\text { groups with real-time } \\
\text { teacher instruction }\end{array}$ & $\begin{array}{l}\text { groups without real-time } \\
\text { teacher instruction }\end{array}$ \\
\hline \multirow[t]{2}{*}{ Providing knowledge } & 1467 & 1899 \\
\hline & $29.3 \%$ & $23.3 \%$ \\
\hline \multirow[t]{2}{*}{ Contextual questions } & 868 & 988 \\
\hline & $17.3 \%$ & $12.1 \%$ \\
\hline \multirow[t]{2}{*}{ Shared problem solving } & 1318 & 1942 \\
\hline & $26.3 \%$ & $23.9 \%$ \\
\hline \multirow[t]{2}{*}{ Management of interaction } & 336 & 514 \\
\hline & $6.7 \%$ & $6.3 \%$ \\
\hline \multirow[t]{2}{*}{ Summing up } & 107 & 142 \\
\hline & $2.1 \%$ & $1.7 \%$ \\
\hline \multirow[t]{2}{*}{ Other input } & 908 & 2651 \\
\hline & $18.1 \%$ & $32.6 \%$ \\
\hline \multirow[t]{2}{*}{ Total } & 5004 & 8136 \\
\hline & $100,0 \%$ & $100,0 \%$ \\
\hline
\end{tabular}


Figure 1. Game levels 1, 2 and 3.

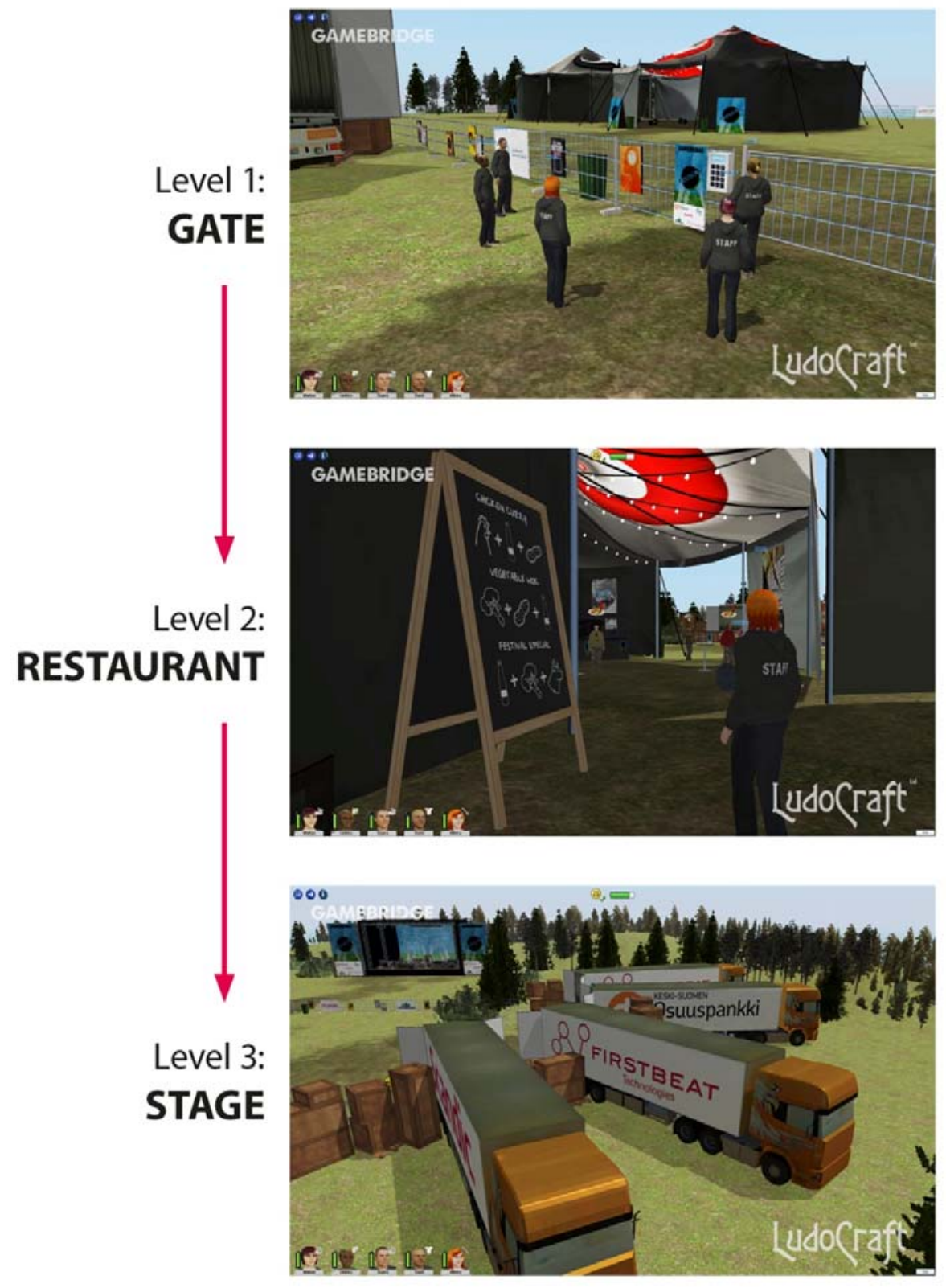

